\title{
A RÚSSIA DO SÉCULO XIX: ENTRE A HISTÓRIA E A LITERATURA
}

\author{
Rafael Marcelino Tayar
}

Universidade do Oeste Paulista - UNOESTE. Pós-Gradução em Educação, Presidente Prudente, SP. E-mail: rafatayar@hotmail.com.

\section{RESUMO}

O objetivo deste trabalho é suscitar atenção de historiadores para a importância da literatura como um documento histórico, que pode em si, contextualizar o passado de maneira singular, permitindo novas visões acerca do mesmo; assim como auxiliar na interpretação social, política e cultural de um período. Para tal, o artigo visa fornecer um estudo da sociedade russa do século XIX, com foco na vida campesina, e seus subsequentes problemas; para então, relacionar e comparar tal conhecimento factual, com a literatura da mesma época, ampliando e diversificando as possibilidades de pesquisa.

Palavras-chave: literatura; servidão; camponês; Rússia século XIX; comportamentos.

\section{THE RUSSIA OF THE 19TH CENTURY: BETWEEN HISTORY AND LITERATURE}

\begin{abstract}
The objective of this work is to raise attention of historians of the importance of literature as a historical document, which can itself contextualize the past in a unique way, allowing new insights about the same; as well as assist in social interpretation, political and cultural life in a period. Therefore, the article aims to provide a study of Russian society of the nineteenth century, focusing on country life, and its subsequent problems; and then relate this factual knowledge to the literature the same epoch, expanding and diversifying the research possibilities.
\end{abstract}

Keywords: literature; servitude; farmer; Russia nineteenth century; behaviors.

\section{INTRODUÇÃO}

A Rússia do século XIX continua assiduamente instituindo grande fascínio, seja pela conturbada situação política vivida nesse período, envolto às guerras contra as forças napoleônicas; a centralização do poder czarista; a ineficiência administrativa do mesmo; e uma economia basicamente agrária, com latifúndios explorados de maneira ultrapassada. Havia um relativo atraso crescente, perante a revolução industrial que acontecera na Europa neste período. (SEGRILLO,2012)

O regime de servidão acontecera durante o império russo, suas motivações e consequências foram explorados pela literatura da época. Para Hobsbawm (2014) a falta liberdade do camponês russo no começo do século XIX era tão grande e evidente que seria difícil distinguir entre servidão e escravidão. Antes do fim da servidão, o servo poderia ser vendido separadamente da terra, como Hobsbawm (2009) nos mostra num anuncio na Gazette de Moscou em 1801:

À venda, três cocheiros, bem-treinados e bastante apresentáveis, duas moças de 18 e 15 anos, ambas de boa aparência e hábeis em vários tipos de trabalhos manuais. A mesma casa tem à venda duas cabelereiras, sendo uma de 21 anos, que sabe ler e escrever, tocar instrumentos musicais e fazer trabalhos de mensageira, e a outra apta a arrumar os cabelos de cavalheiros e damas; vendemos também pianos e órgãos.

(HOBSBAWM, 2014, p. 38- 
Após a derrota na Guerra da Crimeia (1853 a 1856), o atraso tecnológico russo, ficara evidenciado. Sua imagem ficou desgastada com este duro golpe. A força marítima russa não era párea para força naval inglesa e francesa, assim como os primitivos rifles russos colaboraram de maneira crucial para o revés. Após a derrota, o imperador já tinha em mente a sensação que tal guerra causara, e as possíveis comparações tecnológicas com as forças do ocidente (SKOCPOL, 1979). Uma parcela pequena, mas com força política, clamava por modernização econômica. Logo, o governo entendeu que o primeiro passo a ser tomado, visando as possíveis reformas econômicas e estruturais, seria a emancipação dos servos, que representavam, aproximadamente $80 \%$ de toda a população (CHAPMAN, 2001).

Para a nobreza russa, era impensável tal ato, já que segundo Segrillo (2012, p. 154): "Na Rússia o status de um nobre era avaliado não tanto pela quantidade de terras que possuía, mas sim pelo número de seus servos"

Mesmo com demasiada objeção, Alexandre II deixou claro que era melhor a abolição da servidão feita por cima, do que esperar que a mesma começasse por baixo. Discurso que demonstrava o receio de uma possível revolta camponesa. Entretanto, problemas sociais, como a miséria, a pobreza, as doenças e o analfabetismo envolvendo os mujiques $^{1}$, não cessaram com o fim da servidão instituída em 1862 pelo czar Alexandre II. Tais mudanças apenas geraram novos problemas, e revoltas, que eram contidas pelo estado, pois ao fim da servidão, as terras não foram doadas aos servos, já que o governo não tinha intenção de prejudicar a nobreza. Logo, tais terras foram vendidas (SEGRILLO, 2012).

Para os camponeses que não queriam ou podiam pagar o preço dos lotes comuns, havia a opção, em algumas regiões, do chamado "lote de mendigos", que era uma minúscula porção grátis de terra (geralmente insuficiente para

\footnotetext{
${ }^{1}$ Era a denominação dada ao camponês russo, indicativo de certo nível de pobreza, situação social inferior
}

Compreendendo os principais problemas da sociedade russa do século XIX, veremos que fatores como estes, que expuseram e influenciaram ascendentes nomes da literatura russa, a retratarem o abismo social vivido, assim como as diversificadas nuances sentimentais e psicológicas, que estiveram envolto de tal povo. Por conseguinte, entende-se que a realidade social, a conduta e a história de cada época, servira, por muitas vezes, como inspiração para a expressão cultural, e irá contribuir para interpretações de obras literárias, como explica Cândido (2006, p. 13):

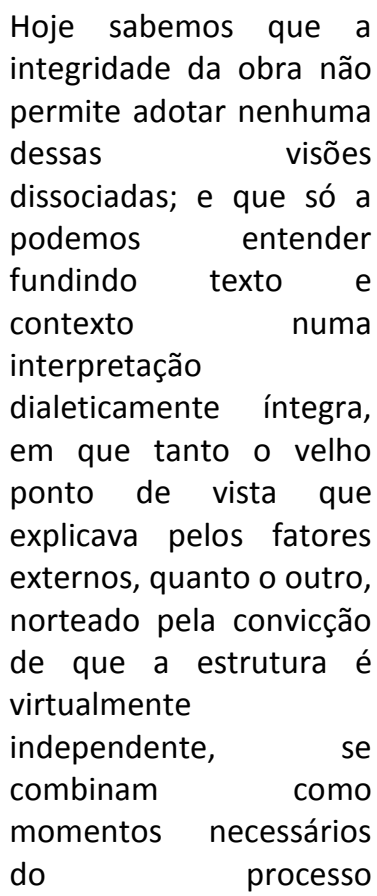
interpretativo. Sabemos, ainda, que o externo (no caso, o social) importa, não como causa, nem como significado, mas como elemento que desempenha um certo papel na constituição da estrutura, tornando-se, portanto, interno.

As angustias, os medos, os pecados e sonhos dos camponeses da Rússia no século XIX, foram consequentemente retratados através de romances épicos, novelas, contos e poesias; e convieram portanto, como um apanhado de momentos singulares, cheios de significação para a compreensão do imaginário de uma época.

No século $\mathrm{XIX}$, a literatura 
russa atingiu seu auge e conquistou o mundo, com Dostoievski e Tolstoi, pontificando em meio a uma série de romancistas que discutiam as grandes questões universais, ao mesmo tempo que refletiam os processos sociais de transformação pelos quais passava o país. (SEGRILLO, 2012, p. 54)

\section{METODOLOGIA}

Em relação aos procedimentos técnicos, a coleta de dados seguiu uma proposta qualitativa, feita através de base bibliográfica, utilizando-se de obras literárias condizentes ao período estudado, para obtenção qualificada de dados que pudessem contextualizar um período (SEVERINO, 2007). As obras foram então confrontadas com o conhecimento vigente, respectivo à saberes já estabelecidos.

Tal posição metodológica, operacionaliza-se com função de desvelar possíveis conexões a serem feitas, entre literatura russa do século XIX, com o saber acadêmico histórico, social e antropológico já assentadas sobre a Rússia do mesmo período, com principal enfoque para o imaginário da época, e a vida cotidiana.

A proposta da pesquisa quanto ao ponto de vista dos objetos, compreende ademais, analisar e refletir acerca dos dados coletados, e efetuar uma pesquisa descritiva, expondo características cotidianas do povo russo do século $\mathrm{XIX}$, estabelecendo relação entre as bases bibliográficas pesquisadas.

\section{RESULTADOS}

A literatura Russa do século XIX compôs um quadro respectivo a vida humana e seus variados aspectos que explicitam para uma Rússia menos distante, com seus laços culturais desenvolvidos na fluidez de cada período.

Mikhail Lomonosov (1711-1765) atuou em diversas áreas, e foi peça fundamental na criação de bases para língua russa da era moderna, o mesmo escreveu contos e prosas, que aproximaram a língua culta, ou antigo eslavo eclesiástico, com a língua popular e mais vulgar, utilizada pelos camponeses. Tal unificação se deve muito à essa gramática, impressa por Mikhail Lomonosov. (SEGRILLO, 2012).
Nikolai Karamzin (1766-1826) foi o mais famoso nome do sentimentalismo literário russo, gênero difundido pelos ingleses na Europa muitos anos antes.

Aleksander Pushkin (1799-1837) considerado maior poeta russo, e como de fato Mikhail Lomonosov criou bases para a para língua russa da era moderna, Pushkin foi considerado o fundador da literatura russa moderna. De acordo com Segrillo (2012, p. 53):

0 escritor incorpora os elementos da língua popular às suas obras de poesia e fiç̧ão (sem vulgarizar a literatura, pelo contrário, dando dimensão literária ao russo cotidiano), criando, assim, as bases da literatura russa da época contemporânea.

\section{DISCUSSÃO}

A interseção entre literatura e história, assessora o pesquisador para novas visões e representações do passado, oferecendo-lhe narrativas que podem exercer importante papel como partes integrantes de contextos sociais, políticos, econômicos e culturais. Essas diversidades de leituras, trazem consigo variados conhecimentos e pontos de vista.

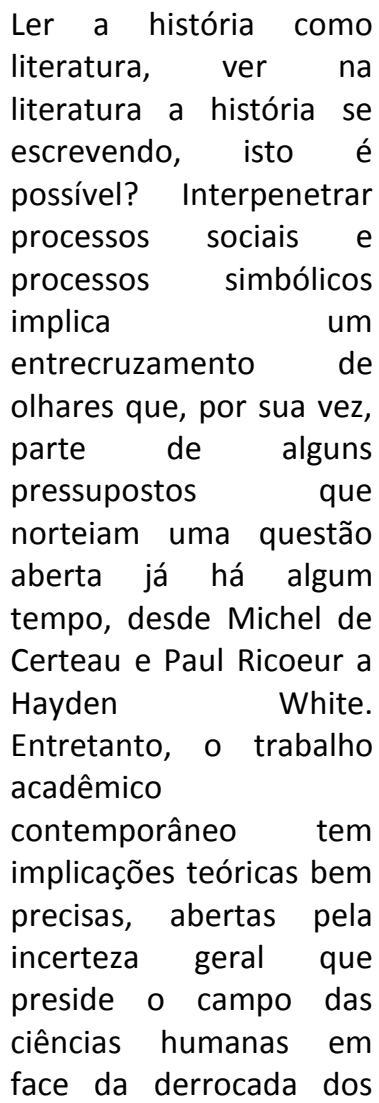


modelos explicativos da realidade. Desta incerteza, reabre-se o debate em torno da verdade, do simbólico, da finalidade das narrativas histórica e literária, da gerência do tempo e da recepção do texto, questões estas que colocam a história e a literatura como leituras possíveis de uma recriação imaginada do real. (LEENNHARDT; PESAVENTO, 1998, p. 910)

A natureza da existência humana, foi explorada de maneira assídua e profunda pela literatura (CÂNDIDO, 2006). Tal abordagem, foi a princípio esmiuçada por escolas literárias na Rússia, como o sentimentalismo, e o romantismo. O movimento estético chamado sentimentalismo, explora a priori sentimentos por vezes exagerados, artificiais; mas normalmente o fazem apoiando-se em acontecimentos cotidianos, que espiados com um viés interrogatório, podem revelar um quadro social da época, contendo conceitos de valores e moralidades impressos em si.

Nikolai Karamzin (1766-1826) foi um importante escritor, poeta e historiador russo. Entre suas obras A pobre Lisa (escrito no final do século $X V I I I)$ demonstra uma tendência entre a virtude que era normalmente associada a modéstia, e o pecado que pelo contrário era considerado algo resultante a riqueza. O conto narra a história de uma família camponesa, onde após a morte do pai, a mãe viúva, encontra-se sem condições físicas para trabalhar, e Lisa, a filha, assume a condição para si. Elas arrendaram sua gleba por uma pequena quantia, e Lisa passa a vender flores na cidade de Moscou.

Importante notar as concepções de prosperidade que uma mãe camponesa poderia almejar para sua única filha antes de morrer, e o afago encontrado na religião:

É no outro mundo, minha gentil Lisa - respondia a velhinha entristecida. - É no outro mundo que deixarei de chorar. Dizem que lá serão todos felizes; talvez me alegre também quando vir o teu pai. Mas agora não quero morrer: o que é que será de ti sem mim? Com quem te abandonarei? Não, faça Deus que antes eu te arrume um bom lugar" Quem sabe se não aparecera em breve um homem bondoso? Então vou abençoa-lo, meus filhos queridos, farei $o$ sinal da cruz e tranquilamente me deitarei na cova úmida. (KARANZIM, 2014, p. 23)

Lisa ainda se apaixonaria por Erast, um jovem fidalgo, e conhecera o pior que o amor pode proporcionar, resultando numa tragicidade típica de tal movimento literário, que representa de maneira romantizada, o espirito de uma época ao retratar o abismo social existente entre Lisa e Erast, assim como conflitos morais concernentes a tal sociedade.

Antes de movimentos sociais que colocariam em dúvida a sociedade russa do século XIX, e os modelos de desenvolvimento praticados até então, o escritor Nikolai Gogol (1809-1851) daria uma visão russa para o gênero realismo fantástico que exploraria o desejo das classes populares, e questionara os valores burgueses.

Em o conto $O$ capote, Gogol explora a história de um homem insignificante, um servidor de nona classe ${ }^{2}$ do império russo, que necessita de um novo capote para proteger-se do frio, já que o seu atual, encontra-se num estado de extenuação incontornável. Porém Akáki Akakievitch, o protagonista, não contem dinheiro o suficiente para compra-lo, mas com muita labuta e economia ele consegue obter o tão sonhado capote.

$$
\text { O frio é um problema real, }
$$
principalmente para as camadas mais necessitadas da Rússia do século XIX:

Existe em Petersburgo um poderoso inimigo de todos os assalariados que ganham quatrocentos rublos por ano ou em torno disso. Tal inimigo é ninguém mais e ninguém

\footnotetext{
${ }^{2}$ Os servidores civis e militares do império russo dividiam-se em 14 classes consecutivas, sendo a 1a (chanceler, marechal de exército ou almirante) a mais alta.
} 
menos que nosso frio boreal, embora se diga, na realidade, que ele é muito saudável. Por volta das nove da manhã, exatamente naquela hora em que as pululam de funcionários rumando ao departamento, ele se põem a dar piparotes tão bruscos e brutos em todos os narizes sem exceção que os coitados funcionários ignoram absolutamente onde os esconder. Neste período, quando até mesmo os titulares dos cargos altos tem frontes doloridas e lagrimas nos olhos, os pobres servidores de nona classe veem-se várias vezes, desprotegidos. (GOGOL, 2014, p. 158)

O conto divaga-se como uma sátira social, provida de uma forte crítica as condições vividas por servidores públicos de uma Rússia burocrática e hipócrita.

$\mathrm{Na}$ tentativa de esmiuçar a miséria do povo russo, Anton Tchekhov ${ }^{3}$ (1860-1904), escritor e médico, escreveu o notável conto "Os mujiques' que narra a história de um trabalhador residente de Moscou, que ao adoecer, viu-se obrigado a demitir-se do serviço. Gastou todas suas reservas com tratamentos, e na escassez de dinheiro para sustentar a esposa e a filha, viu-se numa inerente necessidade de mudar-se para casa de sua família. A mesma residia numa aldeia, e viviam como camponeses, de vida simples e desafortunada.

Percebe-se tal situação logo na chegada Nikolai, o protagonista, quando o mesmo encontra seus familiares pela primeira vez:

Enquanto isso, voltaram os velhos, o pai e a mãe de Nikolai, descarnados, curvados, sem dentes, os dois da mesma altura. Voltaram também as mulheres - as noras, Maria e Fiokla, que trabalhavam do outro lado do rio, na casa de um

\footnotetext{
${ }^{3}$ Considerado um dos maiores contistas de todos os tempos.
}

senhor de terras. Maria esposa do irmão Kiriak, tinha seis filhos, e Fiokla, esposa do irmão Denis, que partira para ser soldado, tinha dois filhos; quando Nikolai, ao entrar na isbá ${ }^{4}$, viu a família inteira, todos aqueles corpos grandes e pequenos que se agitavam nas camas de tábua junto à estufa, nos berços e em todos os cantos, quando viu a sofreguidão com o que os velhos e as mulheres comeram o pão preto, que molhavam na agua antes de mastigar. (TCHEKHOV, 2011, p. 99)

Com a miséria social extremada, e um ambiente degradante, certos discursos passam a ser incorporados, impulsionados pela falta de esperança, de que tal situação poderia um dia contornar-se. A liberdade, mesmo que restrita gera responsabilidades, que pesam demasiadamente. Principalmente para os menos apessoados. Logo surgem pensamentos conservadores:

No tempo da servidão
era melhor - disse o
velho, enquanto enrolava
seda. O sujeito
trabalhava, comia,
dormia, tudo na sua
hora. No almoço, tinha
sopa de repolho e
mingau, de noite
também davam sopa de
repolho e mingau.
Pepino e couve, isso
tinha à vontade: a gente
comia livremente,
quanto a alma quisesse.
(TCHEKHOV, 2011, p.
121)

Os impostos referentes a terra, eram altos, funcionavam como anuidades; eles estendiam-se ao longo de 49 anos. Os altos juros indicavam que o camponês pagou um preço bem mais elevado pela terra do que os padrões de mercado da época. Isto funcionou como uma

\footnotetext{
${ }^{4}$ É uma residência característica camponesa russa, comumente feita com troncos de árvores, com localização próxima de estradas.
} 
compensação aos proprietários antigos que perderam trabalho servil. (WOOD, 2003).

Nessa mesma linha de pensamento, o conto "Os mujiques" fornece-nos uma ideia das dificuldades que o camponês encontrava para pagar estes impostos, e ainda revela consequências que poderiam ser tomadas, caso tais tributos não fossem pagos:

Havia novidades bastante desagradáveis. Em duas ou três casas, haviam confiscado galinhas para compensar os impostos atrasados, mandaram-nas para o governo distrital e lá elas morreram à míngua, porque ninguém Ihes dava de comer; confiscavam ovelhas, e, enquanto as levavam amarradas, mudando de carroça a cada aldeia, uma delas morreu. (TCHEKHOV, 2011, p. 130)

No final do conto, Olga, a esposa de Nikolai, tece comentários de sua experiência morando com os mujiques, definição descritiva que resume costumes locais:

No decorrer do verão e do inverno, houve ocasiões e dias em que aquela gente parecia viver pior do que os animais, viver com eles era horroroso; grosseiros, sujos, sórdidos, sempre bêbados, eles vivem em atrito, não param de brigar, não se respeitam, tem medo $\mathrm{e}$ desconfiança uns dos outros. Quem cuida da taberna e dá de beber as pessoas? 0 mujique. Quem desperdiça e consome em bebida o dinheiro do fundo comunitário, da escola e da igreja? O mujique. Quem rouba vizinhos provoca incêndios de proposito e presta falso testemunho na justiça, em troca de uma garrafa de vodca? Quem, na assembleia do conselho local e em outras reuniões, se pronuncia contra os mujiques? $\mathrm{O}$ mujique. Sim, viver com eles é horrível, mas também são gente, sofrem e choram feito gente, e na vida deles não existe nada que não possa encontrar uma justificação. O trabalho pesado, que faz doer o corpo inteiro de noite, os invernos brutais, as colheitas minguadas, as casas apertadas; e ajuda não vem nunca, nem existe lugar de onde se possa esperar socorro. (TCHEKHOV, 2011, p. 137)

\section{CONCLUSÃO}

A leitura da literatura, contribui como documento histórico, precisando ser devidamente interrogado. Pode-se enxerga-la como um testemunho histórico, pois a mesma representa contextos que se articulam neste processo, e em seus devidos acontecimentos.

Os modos de desenvolvimento das atividades humanas entre si e a natureza, assim como suas práticas econômicas, culturais, políticas, religiosas, intelectuais, podem ser devidamente abordadas através da literatura. $\mathrm{E}$ cabe ao historiador, interpretar tais documentos.

[...] o passado humano não é uma agregação de ações separadas, mas um conjunto de comportamentos intimamente interligados, que têm uma razão de ser, ainda que na maioria das vezes imperceptível para nossos olhos. (KARNAL. 2008, p. 43)

Tais registros muitas vezes imperceptíveis aos nossos olhos, podem ser constituídos com auxílio da literatura. O imaginário de uma época, assim como as representações do passado, são estritamente alcançáveis, com apoio dos estudos literários, que fornecem em si, uma concomitante gama de visões históricas que podem ser recuperadas, não para apresentar trazer o passado tal como ele era, mas traze-lo à tona através do que dela 
ainda sobrevive nos dias atuais; assim, fornecem ao historiador uma nova maneira de interpretar a história.

\section{REFERÊNCIAS}

CÂNDIDO, A. Literatura e Sociedade. 9. ed. Rio de Janeiro : Ouro sobre Azul, 2006.

CHAPMAN, T. Imperial Russia: 1801-1905. London: Routledge, 2001

GOGOL, N. Contos Russos. 1. ed. São Paulo: Martin Claret, 2014.

HOBSBAWM, E. A era das revoluções. 33. ed. Rio de Janeiro: Paz e Terra, 2014.

KARAMZIN, K. Contos russos. 1. ed. São Paulo: Martin Claret, 2014.

KARNAL, Leandro. História na sala de aula: conceitos, práticas e propostas. 5.ed.

São Paulo: Contexto, 2008.

LEENNHARDT, Jacque; PESAVENTO, Sandra Jatahy. (Org). Discurso histórico e narrativa literária. Campinas: Unicamp, 1998
SEGRILLO, A. Os russos. 1. ed. São Paulo: Contexto, 2012.

SEVERINO, A. J. Metodologia do trabalho científico. 23 ed. São Paulo: Cortez, 2007.

SKOCPOL, T. States and social revolution: a comparative analysis of France, Russia and China. Theory and Society, New York, v. 7, n. 2, 1979, p. 7-95. https://doi.org/10.1017/CB09780511815805

TCHEKHOV, A. O assassinato e outras histórias. 3. ed. São Paulo: Cosac Naify, 2011.

Recebido para publicação em: 24/04/2016 Revisado em: 27/04/2016 Aceito em: 30/04/2016 